\title{
Sociedad civil y exclusión en Ciudad Juárez. Consideraciones desde las asociaciones de mujeres
}

\author{
Carlos Arturo Martínez Carmona \\ FLACSO, México \\ Email: arturo.martinez@flacso.edu.mx
}

\begin{abstract}
Resumen: ${ }^{1}$ Considerando la propuesta de sociedad civil desde la perspectiva de sociología cultural planteada por Jeffrey Alexander, este documento refiere al análisis del discurso mediante el cual las asociaciones de mujeres en Ciudad Juárez identifican las formas de exclusión situándolas en una categoría de lo profano a partir de su acción pública, y la forma en la que éstas sacralizan discursivamente los procesos de inclusión en la sociedad civil. A partir de un conjunto de entrevistas realizadas a un grupo de activistas de tres asociaciones civiles se reconocen los elementos discursivos que ofrecen un panorama de su acción y visión, como parte del movimiento social que lucha y demanda contrarrestar la violencia y la exclusión de las mujeres. A pesar de la intromisión de las esferas privadas en la configuración de la sociedad civil, el discurso basado en derechos y la capacidad organizativa del movimiento ha permitido dar pasos paulatinos en la inclusión del grupo minoritario.
\end{abstract}

Palabras clave: ciudadanía, esfera civil, exclusión, movimiento de mujeres.

\section{Civil society and exclusion in Ciudad Juárez. Considerations from women associations}

\begin{abstract}
Considering the proposal of civil society from the perspective of cultural sociology proposed by Jeffrey Alexander, this essay refers to the analysis of discourse by which the associations of women in Ciudad Juárez identify the forms of exclusion placing them in a category of the profane based on its public action, and the way in which these processes discursively sacralize inclusion of women in civil society. From a series of interviews with a group of activists from three civil associations the discursive elements that provide an overview of its action and vision, as part of the social movement and demand struggling against violence and the exclusion of women in the civil sphere, are recognized. Despite the intrusion of the private sphere in shaping civil society, rights-based discourse and organizational capacity of the movement has allowed gradual stepping on the inclusion of the minority group.
\end{abstract}

Key words: citizenship, civil sphere, exclusion, women movement.

\section{A sociedade civil e da exclusão em Ciudad Juarez. Considerações desde as associações de mulheres}

Resumo: Considerando a proposta da sociedade civil sob a perspectiva da sociologia cultural representada pelo Jeffrey Alexander, este documento refere-se à análise do discurso pelo qual as associações de mulheres em Ciudad Juárez iden- 
tificar formas de exclusão colocando-os em uma categoria do profano a partir de sua ação pública, e como esses processos discursivamente consagrar inclusão na sociedade civil. A partir de uma série de entrevistas com um grupo de ativistas de três associações civis é reconhecido elementos discursivos que fornecem uma visão geral de ação e visão como parte do movimento social que exige lutar contra a violência ea exclusão das mulheres. Apesar da invasão da esfera privada na formação da sociedade civil, o discurso baseado em direitos ea capacidade de organização do movimento levou a passos graduais para inclusão do grupo minoritário . mulheres.

Palavras-chave: cidadania, esfera civil, a exclusão, o movimento das

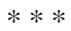

\section{Sociedad civil y procesos de exclusión e inclusión}

La idea de sociedad civil lleva aparejada el acceso a derechos diversos por parte de sus miembros mediante la categoría de ciudadanía, derechos que atraviesan por la defensa y la seguridad (civiles), elección de los gobernantes (políticos) y acceso a un cierto nivel de bienestar (sociales) (Marsall, 1964). Sin embargo, en términos concretos la idea de ciudadanía conlleva otros tantos elementos con pesos y gradaciones diferentes lo que impiden pensar en un concepto uniforme y unitario. Se ha considerado así tanto la participación, los derechos, la pertenencia a una comunidad política, las relaciones con el Estado, entre otros (Bobbes, 1995).

Desde la concepción liberal, la extensión de la ciudadanía conlleva la dotación de derechos y obligaciones por igual a los miembros de un Estado-nación. Desde esta perspectiva la categoría de ciudadanía ha sido considerada con un carácter de principios universalizantes que concibe a las personas en igualdad de condiciones al momento de su incursión en la vida pública de una comunidad. En estos términos la idea de ciudadanía universal esto es destacando lo que los individuos tienen en común, y leyes y reglas del mismo carácter para todas las personas- posee características homogeneizadoras, presentándose como antítesis a lo diferente y aplicando la lógica de los derechos y las obligaciones haciendo tabula rasa, es decir, sin reconocer a los históricamente excluidos por condiciones de raza, género, estatus migratorio, preferencia sexual, entre otros (véase Young, 1996; Janoski, 1998).

La ciudadanía se encuentra asentada en el principio de mayoría, es decir, expresa la voluntad general superando las diferencias particulares, por otro lado, ahí donde las diferencias son exacerbadas el seguimiento de un principio de tratamiento igualitario generalizado puede perpetuar las desventajas y la opresión, lo mismo ocurre cuando ciertos grupos de poder influyen en la determinación de la definición de la ciudadanía para todos. Las minorías, por el contrario, refieren a los grupos sociales que son superados por las condiciones de la ciudadanía universal o de mayorías. Aquí las diferencias no se apoyan en una diferencia de carácter cuantitativo, sino 
cualitativo mediante factores como la explotación, marginación, falta de poder, imperialismo cultural, violencia, y/o discriminación (Young, 1996:111). De este modo la limitación al ejercicio de derechos puede ser una consecuencia deliberada o efecto de la operatividad de la ciudadanía universalizante.

Por otro lado, asentada en la sociedad civil, la idea de ciudadanía surge en un territorio y para una comunidad, ser ciudadano implica ser parte de ese grupo organizado reconocido por su identidad, el ser parte de una nación, una comunidad imaginada. Pensar en la sociedad civil implica tomar en cuenta los procesos de formación y constitución de la ciudadanía en diferentes contextos (Khilnani citado en Massal, 2007). Esto signica que existen diferentes configuraciones de sociedad civil en los distintos contextos nacionales o regionales, pero también existen diferentes trayectorias (subnacionales y supranacionales) a disposición de la sociedad civil, para extender la ciudadanía y la democracia (Massal, 2007). En esta lógica la idea de una sociedad civil real implica que esta se encuentre diferenciada de nación a nación, de espacio territorial a espacio territorial, pero que las diferentes realidades pueda ser también referentes mutuos ${ }^{2}$. Sin embargo, como menciona Alexander, el Estado-nación continúa formando lazos efectivos de la sociedad comunal, y es típicamente una versión nacional de los lazos solidarios la que define los derechos y deberes de aquellos que son sus miembros y determinan la inclusión y exclusión como resultado (Alexander, 1997:123). Es necesario por ello entender cómo se configura la sociedad civil, cómo se elaboran los discursos de la ciudadanía, y conocer cuál es la lógica en estos principios de exclusión.

La propuesta de sociedad civil que abre desde la sociología cultural Jeffrey Alexander tiene un carácter práctico y realista, es decir, se reconoce desde su apartado solidario, empírico y real (Alexander, 2000, 2006) ${ }^{3}$. Desde esta perspectiva, la sociedad civil se considera como un espacio de disputa guiada por un sentido utópico de comunidad no realizable, pero deseable. Este es un locus que se caracteriza por la universalidad vs el particularismo, pero que su principio solidario le evoca dinamicidad, ya que identifica inclusiones y exclusiones (tanto de grupos, valores, ideas) de acuerdo con la manera en la que las otras esferas no civiles o privadas como la religión, la familia, el gobierno y la economía infieren e intervienen en la sociedad civil. Encontramos, entonces, a la sociedad civil como una esfera de solidaridad en la que el universalismo abstracto y las versiones particularistas de la comunidad se encuentran tensamente entrelazados (Alexander, 2000: 142). Desde esta perspectiva la sociedad civil remite a una arena en las cual la solidaridad social es definida en términos universalistas. Esto es la nosotridad (we-ness) de una comunidad nacional toma en una fuerte posibilidad de sentido, el sentimiento de conectividad con cada miembro de la comunidad que trasciende cometidos particulares, estrecha lealtades e intereses sectarios (Alexander, 1997:118).

El universalismo puede tender a ser parcialmente dominado por ciertas esferas, pero siempre y en todo momento tiende a su expansión median- 
te la reforma y el monitoreo. De este modo, la sociedad civil trata de enmendar las exclusiones, Alexander menciona, en respuesta a lo que puede llamarse una intrusión destructiva dentro del reino civil, la sociedad civil debe hacer esfuerzos en la reparación del o los daños sobre los excluidos (Alexander, 1997: 129).

Las exclusiones que se encuentran distribuidas en el espacio de la misma sociedad civil pueden, y en realidad suelen pasar inadvertidas, sobre todo porque a lo largo del tiempo se desarrollan una serie de códigos, metáforas y arquetipos que normalizan las exclusiones, de hecho para estos mismos grupos suele ser algo consustancial a su mundo de vida. Estas delimitaciones de la misma esfera civil en los hechos utilizan códigos binarios de ciudadano/enemigo, puro/impuro dentro de la sociedad civil, considerando al ciudadano (puro) como aquel que se encuentra y forma parte de la sociedad civil, y al enemigo (impuro) como aquel que está por fuera de los marcos motivacionales, relaciones e institucionales que la propia sociedad civil ha dispuesto (Alexander, 2000), es importante señalar que estos marcos se definen en una sociedad civil real mediante la concreción de su particular en el universalismo ${ }^{4}$. Si se piensa a la sociedad civil como un espacio de disputa discursiva para instalar los principios universalistas por encima de los privados, se pensaría que aquí existe una contradicción con lo planteado anteriormente a propósito del acceso a derechos vía la ciudadanía universalizante. Universalización en este caso implica ampliación del abanico de derechos -lo que abarca a los excluidos- y produce efectos en la reparación del daño -por ejemplo en políticas de acción afirmativa- en un sentido solidario, y bajo principios de humanidad.

En este sentido se puede observar que para Alexander la ciudadanía refiere a un carácter colectivista de ciudadanía, en comparación con la mirada liberal-pluralista. Aunque, advierte que si la solidaridad se volcará sólo hacia la colectividad se convertiría en un particularismo apoyando la represión y no la libertad (Alexander, 1997). Aunque el carácter distintivo es considerar a la ciudadanía en disputa, y redefinición a través de un proceso de exclusión-inclusión, de lo profano-sacro implicando un ideal de igualdad, homogeneidad, universalidad en donde fácilmente se produce la desavenencia, la confrontación, un nosotros y un ustedes (Bobes, 2002). Es en esta lógica en la cual se codifican los derechos individuales que excluyen a diferentes grupos sociales minoritarios, entre ellos a las mujeres. Esto es así en comparación con sus pares varones con diferentes implicaciones de grado e impacto en cada realidad social, en cada referente de sociedad civil.

¿Qué permite el cambio en estos procesos de redefinición de la ciudadanía en la sociedad civil? De acuerdo con Alexander la constitución, los procesos, y las exigencias, y éxitos de los movimientos sociales se enmarcan e interaccionan con la esfera civil real a la que se refieren. Es debido a este surgimiento paralelo y a su referencia mutua que ambos no pueden ser entendidos de manera aislada, ni los movimientos sociales han generando sus propias dinámicas para concretar sus objetivos aislados o marginados de la esfera civil, ni estos dirigen exclusivamente su desenvolvimiento, acciones 
y energías contra el Estado, sino hacia la sociedad civil misma. A partir de la organización de la acción colectiva se presentan las inconformidades particularistas mediante las instituciones de comunicación generando una traducción de sus demandas y problemas particularistas- en códigos de carácter universalizante, esto es traducir experiencias de lo particular a lo general, de lo mundano a lo civil y de regreso (Alexander, 2006:231).

Tanto en la conformación como en la reproducción de la esfera civil el papel de la traducción de la exclusión en códigos solidarios o civiles, corresponde ampliamente a los movimientos sociales. Estos se convierten indirectamente en agentes de regulación dentro de la esfera civil. No solo es mediante su presencia en la escena pública, sino mediante la acción discursiva y performativa, que se puede reforzar lo civil universal al reducir la injerencia de las otras esferas no civiles, motivando a la regulación vía legal e institucional para ejercer sanción, control o monitoreo de estas esferas.

La lealtad y solidaridad que los movimientos sociales despierten en la esfera civil tendrá impactos en la construcción de nuevas formas de significado y de identidad grupal y personal. De este modo, para lograr ser exitosos los movimientos sociales no pueden ser vistos como una respuesta a problemas realmente existentes, sino como una presión generada para un tipo particular de economía, Estado, geografía, ley, familia, sistema racial o étnico, o dominio científico (Alexander, 2006:230). Es probable que sin la puesta en escena de manera comunicativa de los problemas que los movimientos sociales traducen en la esfera pública y sus propuestas de cambio social, estos hayan sido trivializados por el conjunto de ciudadanos, y hasta reproducido su desavenencia a estos mediante los códigos binarios en el pasado. De este modo, es en el proceso de construcción de nuevos significados, en la influencia ejercida sobre la modificación de leyes, y en la creación de control ante la intrusión de las otras esferas no civiles, que depende el éxito de los movimientos sociales. Es por ello que la acción colectiva puede ser entendida como una pelea por la posición vis-á-vis las antipatías categoriales de la vida civil: una lucha para representar a otros en categorías negativas y contaminadas y re-presentarse a sí mismos en términos de lo sacro (Ibid: 231).

Los movimientos sociales deben enfocarse en modificar el discurso binario que ocurre en tres niveles: motivos, relaciones e instituciones. Los motivos son atribuidos a los actores políticos en respuesta a la pregunta que parece ser inmanente a la vida civil democrática: qué tipo de personas son necesarias para formar una democracia viable. Las relaciones sociales, son conceptualizadas como legitimas e ilegitimas en respuesta a la pregunta: cómo se relaciona la gente civil y la no civil. Finalmente, las instituciones son categorizadas en respuesta a la pregunta, qué tipo de organizaciones deberían ser formadas por este tipo de personas con este tipo de relaciones (Alexander, 2006). Dada la estructura discursiva de lo motivos y las relaciones cívicas no debería sorprender que esta serie de homologías y antipatías se extienden hasta la comprensión social de las propias instituciones políticas y legales (Alexander, 2000). 
De este modo se trata en este documento, desde lo que anota Geertz (1989), de construir los modos de expresión de los actores, lo que denomina sus sistemas simbólicos. Para ello entonces es necesario ordenar la lógica del grupo de estudio, descifrar y comprender desde que punto de partida las mujeres hablan y expresan su sentir a propósito de su participación en el movimiento de mujeres, las exclusiones a las que se enfrentan y las referencias al cambio en el discurso intrínseco en sus narrativas. Esto permite ofrecer visos de las acciones performativas y dramatúrgicas que impulsan para dar un vuelco en la esfera civil, donde su referencia a lo solidario y moral les permita su carácter de inclusión y el alcance de su ciudadanía que no sea limitativa, sino expansiva.

\section{Una aproximación a la exclusión de las mujeres en Ciudad Juárez}

En términos generales, originariamente la sociedad civil se caracterizó por dejar fuera a las mujeres como participantes de la vida pública y política, dotando de derechos políticos a los varones, y determinando su representación ante los miembros de su familia. Cada sociedad civil de manera diversa conforme ha ido confrontado diferentes procesos sociopolíticos, económicos e históricos ha ido configurando los límites de la ciudadanía en lo formal y lo informal para las mujeres y estableciendo diferentes procesos de exclusión-inclusión.

A partir de la década de los noventa en la frontera norte de México se han registrado de manera persistente una serie de asesinatos de mujeres. Diferentes académicos, asociaciones e instancias internacionales consideran que los crímenes son la punta del iceberg de un fenómeno que tiene mayores alcances sociales, la violencia sistemática hacia las mujeres en la sociedad juarense y su exclusión como grupo minoritario (véase Pérez, 2011; Monárrez, 2007, entre otros). Esto se traduce en la poca capacidad de alcance de derechos sociales, laborales, médicos, seguridad, políticos, entre otros.

En Ciudad Juárez asistimos a una sociedad civil que se encuentra potentemente invadida por la esfera íntima, la esfera económica y la esfera gubernamental. Al respecto Alicia Schmidt (2007) ha puntualizado de manera muy atinada tres elementos que se traslapan con la exclusión del carácter ciudadano de las mujeres: 1 ) una consideración desde la esfera privada de las relaciones de patriarcado como un factor que está inmerso en la sociedad de manera tradicional; por otro lado, 2) las mujeres han encontrado una nueva ventana de oportunidad con efectos perversos, la instalación de la industria maquiladora que las emplea, pero que les ofrece condiciones poco favorables a su crecimiento, las considera como objetos desechables de manufactura, y 3) las instancias gubernamentales que limitan y restringen los derechos -a todos los ciudadanos pero particularmente a las mujeres- desconociendo en cierto momento la violencia enfocada ha- 
cia las mujeres, impidiendo su acceso a la seguridad y a otros derechos. Estas tres formas de exclusión de las mujeres se encuentran entrelazadas y cada una reproduce a las otras de manera interactiva y combinada, lo que la ubica en condiciones de vulnerabilidad, desde la perspectiva de minoría ciudadana.

En casi todas las sociedades el patriarcado ha sido el eje de la exclusión una intromisión de la esfera íntima en la esfera civil. En los discursos de políticos y encargados de preservar la seguridad se observa esta lógica, por ejemplo, Barrio Terrazas gobernador durante el periodo 1992-1998 mencionaba en una entrevista que las mujeres no deben entrar en confianza con la gente de bandas que luego se convierten en sus agresores, pero más aberrante aun fue su declaración acerca de que el feminicidio era culpa de las mismas mujeres por provocar a los hombres, al usar minifaldas y exhibirse en las vías públicas. Uno de los funcionarios del gobierno estatal en ese entonces, José López, proponía que las mujeres deberían auto-aplicarse un toque de queda evitar salir de sus casas y en caso de ir al trabajo, salir y regresar a casa, lo que permitiría reducir el asesinato de mujeres (véase Portillo, 2001). Además ha sido común que los impartidores de justicia desde policías hasta ministerios públicos pregunten a sus familiares si las mujeres tenían una doble vida, es decir, si se dedicaba a la prostitución u otra actividad ilícita, infiriendo que esta condición es limitante de sus derechos. Estas narrativas, como bien apunta Wright (2007), hablan que la víctima de la violencia o del secuestro no estaba donde debería haber estado: en la casa, en el espacio privado, en el lugar que la sociedad civil ha destinado a las mujeres, el espacio de lo íntimo.

Dado que las mujeres particularmente migrantes y de escasos recursos- en Juárez han jugado un papel importante en el trabajo de producción de bienes de la industria, su presencia en el trabajo se equipará con el carácter de mujeres libertinas o prostitutas. Esta idea se ha fundado en los servicios de diversión nocturna prostitución, alcohol y drogas, y los juegos de apuesta- que tradicionalmente ofrecía la ciudad a los varones tanto extranjeros del país vecino, los Estados Unidos, así como los pobladores locales y en tránsito. El papel de la mujer se fue cimentando y reproduciendo como un producto de consumo dado que era el único espacio visiblemente público que podía ocupar, esto de alguna manera implica una forma de ver a las mujeres que se traslada a sus actuales fuentes de trabajo, como lo es en la industria maquiladora.

El carácter económico en el que se ha fundado la ciudad en las últimas décadas representa una fuente de exclusión para las mujeres. El proyecto nacional elaborado para la frontera del norte del país radicó en la atracción de inversión extranjera directa, la oferta de mano de obra barata y un espacio estratégico por su cercanía con el mercado de los Estados Unidos. Esto promovió una fuerte masa migratoria de mujeres de escasos recursos atraídas por la oferta de contratación en actividades de los sectores de la producción. La llamada industria maquiladora prefiere ofrecer empleo a las mujeres dado una asalariada recibe por el mismo trabajo una 
remuneración menor en comparación con un par varón. Aunque, al contrario de lo que se podría suponer que el empleo empodera a las mujeres, termina atándolas a la sobre explotación (mano de obra que se prefiere y al acceso a un empleo con pocas garantías de estabilidad laboral y crecimiento). Aquí tanto esfera íntima como económica se entremezclan para generar un discurso en donde se considera como objetos desechables a las mujeres (Schmidt, 2007). Para la esfera íntima paradójicamente, la venta de mano de obra, se equipará con la venta sexual de su cuerpo. Schmidt menciona El discurso moral que conecta a las obreras con las prostitutas oculta el interés del Estado en la sexualización del trabajo femenino, y le otorga legitimidad a la exclusión de las mujeres subalternas de la esfera protectora de la ciudadanía (Ibid: 29).

Una de las muestras más claras del deterioro de la ciudadanía de las mujeres y que engloba y contiene a las otras formas de exclusión, es la violencia sistemática que se traduce en los brutales asesinatos del que cientos de mujeres han sido víctimas. El feminicidio, como una categoría discursiva apropiada por las mujeres activistas juarenses, patenta la inoperancia del Estado ante otras fuerzas lo que imposibilita el pensar a las mujeres libres de violencia. Fue a partir de 1993 que se encontraron diferentes cadáveres de mujeres violentadas sexualmente, torturadas y asesinadas. A la fecha se han encarcelado a varias personas, sin embargo, los asesinatos no han sido esclarecidos, tampoco han sido contenidos. La violencia como el más amplio referente de exclusión de derechos margina y debilita la actuación de las mujeres, las sitúa en relaciones de opresión y represión en el mundo del trabajo, en el ámbito familiar, en el marco de sus relaciones con el gobierno, en su vida cotidiana.

\section{Las asociaciones y el movimiento de mujeres}

Las asociaciones voluntarias y los movimientos sociales en los últimos años en México han sido reconocidos dada su reciente visibilidad en los ámbitos político, social y económico. Estos han sido considerados como agentes importantes ante la apertura político-electoral, el desentendimiento e incumplimiento de las obligaciones del Estado, y el debilitamiento de la estructura de relaciones corporativistas. A pesar de esto, la apertura para los nuevos sujetos políticos y nuevos espacios para la política ha llegado a Ciudad Juárez de manera tambaleante y se ve filtrada por la exclusión a las mismas mujeres que pertenecen a dichas asociaciones. Sin embargo, las asociaciones no han dejado de hacer patente las condiciones de exclusión a pesar de ser ellas mismas foco de amenazas, desapariciones forzadas y asesinatos. Es por ello, que el carácter de las activistas, las asociaciones y los movimientos sociales en Ciudad Juárez y en todo Chihuahua cobra especial relevancia e interés.

El grupo excluido, y por ende minoritario de mujeres, en Ciudad Juárez no podría ser considerado como tal hasta que se constituyó y conformó, y adquirió cierta identidad como grupo social (Young, 1996). Tanto 
familiares de las víctimas, y posteriormente diferentes asociaciones conformadas por mujeres locales de clase media, universitarias, profesionistas y jubiladas fueron quienes dieron voz al grupo social minoritario, que en este caso no correspondía exclusivamente a mujeres con características particulares, sino a las mujeres en el sentido más amplio, en su carácter de ciudadanas con derechos.

Ante el fenómeno lacerante de una parte excluida de la ciudadanía, un segmento de estas mujeres ha producido acciones colectivas que las encaminan en una pendiente muy sinuosa a la recuperación de sus derechos, al reconocimiento y acceso equitativo, pero diferenciado de ser ciudadanas, a considerarse e identificarse como grupo social minoritario, y exigir la reparación del daño.

La problemática que hace más evidente la exclusión, el feminicidio, ha sido acompañada por la desatención del gobierno local, estatal y nacional. Ello ha implicado toda una serie de procesos de interacción entre diferentes agrupaciones nacionales e internacionales y por ende la constitución de diferentes redes. La tónica ha sido la continuidad del reclamo y la exigencia de la demanda, la profesionalización de las mujeres miembro en los temas, un expertise que han ido adquiriendo para manejar su discurso adecuado a los derechos humanos, y tratar de filtrar su reclamo al nivel de la sociedad civil. Traducir, parafraseando lo mencionado por Wright (2007), un problema que es privado como la pérdida de un familiar a un asunto público la violencia hacia las mujeres; es decir, encumbrar en la esfera civil lo público en denostación del imperativo privado e íntimo con respecto a la exclusión de las mujeres.

A partir de los asesinatos de mujeres y los cuerpos encontrados en los márgenes de las localidades de la entidad, las asociaciones de mujeres comenzaron a conjuntar esfuerzos, primero para hacer visible el fenómeno y generar los reclamos y denuncias correspondientes, posteriormente para concretar todo un movimiento que pugnara por erradicar la violencia y la pobreza con características de género ${ }^{5}$. Las asociaciones y su movimiento, sin embargo, se han enfrentado a importantes dificultades como lo es la desatención del gobierno y la violencia sistemática proveniente desde diferentes frentes hacia las mujeres y hacia las activistas.

Por otro lado, de acuerdo con lo señalado por las mujeres entrevistadas $^{6}$ que forman parte del movimiento se puede considerar que los valores que se han promovido y las estrategias que estas han producido les permiten cierto nivel de éxito (véase cuadro 1). Sus objetivos generales se concentran en el cambio de valores respecto a la equidad de género, la erradicación de la violencia, la pobreza y en general la exclusión de las mujeres. Estos objetivos se han ido concretando paulatinamente como mencionó una de las entrevistadas la política va ahí funcionado lentamente 7 . Tanto el sistema de valores como las estrategias adoptadas permiten observar este logro gradual de objetivos y la permanencia del movimiento. Los principales valores en los que se sustenta el movimiento de mujeres en el 
estado de Chihuahua son la solidaridad, la identidad, y la valentía ${ }^{8}$. La solidaridad refiere a las acciones de las mujeres y las asociaciones con respecto a sus pares para generar apoyos, lo que se traduce en cooperación y confianza entre las mujeres del movimiento, y de aquellas que son beneficiadas por las acciones de las asociaciones. Cuando se realizó la marcha mundial de las mujeres a Nueva York en el año 2000, una de las entrevistadas señala lo siguiente:

Nos fuimos en autobús, de aquí salieron tres camiones y pasamos por diferentes lugares, nos encontramos con mujeres y ahí fue muy comprometedor escuchar mujeres que depositaban su esperanza en nosotras, las que íbamos allá, las que íbamos a estar en el sitio de las Naciones Unidas.

Por otro lado, se encuentra la idea de un nosotras, que les permite generar identidad y distinción, respecto a otro tipo de asociaciones que igualmente puede estar conformadas por mujeres pero que se dedican a otros temas, particularmente aquellas de carácter asistencial ${ }^{9}$. El factor de identidad es clave porque permite reproducir los valores al interior del grupo, dar consistencia y solidez a pesar de las diferencias, y definirse como grupo minoritario. Al respecto menciona una activista de MXM se dan envidias y disentimos, pero nos unen intereses comunes como el luchar por la justicia, el reclamar por que se aclaren los asesinatos, porque se erradique la violencia, y eso nos une y ahí si marchamos, como dicen "hombro con hombro, codo con codo”.

\section{Cuadro 1. Características del movimiento de mujeres en Chihuahua}

\begin{tabular}{|c|c|}
\hline Caracteristicas & Códigos \\
\hline \multirow{8}{*}{ Valores } & Solidaridad \\
\hline & Nosotras \\
\hline & Confianza \\
\hline & Cooperación \\
\hline & Interacción \\
\hline & Valentia \\
\hline & Capacidad \\
\hline & Voluntad \\
\hline \multirow[t]{4}{*}{ Temas } & Miedo cultural ancestral \\
\hline & Pobreza \\
\hline & Violencia \\
\hline & Valores \\
\hline \multirow[t]{11}{*}{ Estrategias } & Logros \\
\hline & Redes \\
\hline & Empoderamiento \\
\hline & Persuasión \\
\hline & Acciones \\
\hline & Aprendizaje \\
\hline & Comunicación \\
\hline & Diversificación \\
\hline & Motivación \\
\hline & Aliados \\
\hline & Injerencia \\
\hline
\end{tabular}


La valentía remite a la idea de que al pertenecer al movimiento las mujeres se han empoderado, frente al gobierno, la esfera privada, la delincuencia y la violencia que las acosa diariamente. El movimiento no se podría entender sin la persistencia de sus integrantes, sin la confianza en que además de promover un cambio social, existen lógicas que las potencian, que les dan fuerza.

Desde luego estos valores no serían del todo efectivos si no existieran las estrategias que le dan carácter al movimiento. Este se reconoce como un movimiento basado en principio de red, existen redes a nivel local -en la ciudad de Chihuahua, en Ciudad Juárez-, y a nivel estatal; estas redes a su vez se han vinculado con otras redes nacionales e internacionales de mujeres y de derechos humanos. Esto es lo que en los códigos de las narrativas se reconoce como diversificación, aliados y redes. La estructura de red ha permitido una fuerte injerencia en la esfera pública, concretar avances en políticas públicas con los gobiernos local y estatal, así como la conformación de diferentes instancias dedicadas exclusivamente a atender las problemáticas que el movimiento demanda y promueve ${ }^{10}$. Al respecto una de las activistas de la Red Mesa de Mujeres menciona:

por ejemplo nosotras también tenemos lazos con el movimiento de mujeres de la ciudad de Chihuahua, entonces ellas para todas sus acciones, pues siempre trabajan en lo colectivo, también es muy claro que no podemos avanzar y no podemos lograr gran cosa si trabajamos más como a nivel individual es muy, muy difícil, entonces por ejemplo, para empujar cuestiones que tienen que ver con el tema de las legislaciones, como la ley que se aprobó en el 2007 aquí en el estado, la ley estatal del derecho de las mujeres a una vida libre de violencia no la hubiera podido impulsar una sola organización.

Los logros por una parte, como la emergencia de aliados locales nacionales e internacionales generan motivación en el movimiento. Pero no solo eso, también el acceso a la información, la comunicación, el constante aprendizaje potencian la acción colectiva de las mujeres en la entidad. En definitiva, la red del movimiento de mujeres en Chihuahua ha permitido hacer pública una demanda, traducir los asesinatos de mujeres y la violencia persistente y sistemática en un movimiento social el que procura modificar los márgenes de la esfera civil en un sentido de inclusión.

\section{La construcción discursiva de la inclusión-exclusión desde las asociaciones}

En la construcción del discurso de las mujeres entrevistadas se puede observar la manera en la que estás promueven y consideran deben ser entendidos los atributos para poder ser parte del espacio público, ellas desde luego abrevan de un discurso por una parte que proviene de la sociedad civil que se está reconfigurando en México después de los cambios en el 
sistema político de reciente data, pero también refieren a un discurso más amplio del que cada vez se extiende más en el mundo. El movimiento de mujeres retoma un discurso de sociedad civil de carácter global, es decir, atrae los discursos que refieren a lo sacro en el mundo de la discusión de lo civil, desde una perspectiva de derechos humanos. En esta lógica se trata de colocar al otro: al que difumina sus derechos, al que no los observa, al que los invisibiliza, al que las excluye, del lado de lo profano, lo no civil, lo privado.

En esta construcción binaria las informantes apuntan las siguientes consideraciones respecto a los motivos, las relaciones y las instituciones, es decir, los atributos, la forma de interactuar, la forma de las organizaciones que derivan de las personas y sus interacciones, para entender de acuerdo con su discurso a una sociedad civil sacralizada, no excluyente de los temas que promueven las mujeres. Al mismo tiempo, postulan la construcción de los contracódigos que desde lo profano se producen para evitar que los temas de inclusión se reproduzcan (véase cuadro 2).

Por cuestiones de espacio resulta imposible hacer el tratamiento de todos los códigos aquí apuntados, por lo que a continuación se tratará solo una selección de los mismos para identificar su construcción y situarlos en la disputa por la exclusión-inclusión de las mujeres.

\section{Cuadro 2. Inclusión/exclusión desde el discurso del movimiento de mujeres}

\begin{tabular}{l|lll}
\multicolumn{1}{c}{} & MOTIVOS & RELACIONES & INSTITUCIONES \\
\hline Código & Reconocimiento & Visibilizar & Justicia \\
& Sensible Sensatez & En el papel & Igualdad \\
& Trabajo/Fuerza & Justo & Eficacia \\
& Valentía & Seguimiento & Inclusión \\
& Profesional & Confianza/cooperación & \\
& Voluntad & Equidad & \\
\cline { 2 - 4 } Contracódigo & Minimizar & Invisibilizar & Injusticia \\
& Insensible & En el papel & Jerarquía \\
& Protestar/ quejarse & Hacer trampa & Ineficacia \\
& Miedo ancestral & Desinterés & Exclusión \\
& Político/funcionario & Desconfianza & \\
\cline { 2 - 3 } & Pasividad & Patriarcado & \\
\cline { 2 - 3 } & & & \\
\end{tabular}

Durante la capacitación que la asociación Mujeres por México impartía a funcionarios de gobierno, cuenta una entrevistada que un asistente comentó ¡qué bueno que no soy mujer, que bueno que soy hombre!, después de hacer visible lo invisible. Pero nuestra informante, en tono de sarcasmo, apuntó Qué bueno que soy mujer porque eso me permite muchas cosas, en cambio de hombre hay muchos aliados del patriarcado, fanatizados del patriarcado (risas). Este argumento retórico permite observar cómo la labor del movimiento y sus asociaciones han sido visibilizar, evidenciar, 
hacer pública la condición de las mujeres en la sociedad chihuahuense, y al mismo tiempo, identificar que aquello que las sitúa en una condición de diferenciación pertenece a lo profano, a la invasión de la esfera privada en la civil.

El ser un fanatizado del patriarcado es una institución social que proviene de las relaciones basadas en la jerarquía y no en la equidad o la igualdad. Es la clara intrusión de la esfera de la intimidad en la esfera civil, ante la cual se trata de generar un contra-discurso, en este caso, mediante el sarcasmo. El carácter de la intromisión de lo íntimo en público ha dado pauta a la organización por parte de las asociaciones, desde fines del siglo pasado, de una infinidad de seminarios, diplomados, capacitaciones primero entre las mismas asociaciones, posteriormente en los espacios universitarios, y las agencias gubernamentales y las empresas que se han mostrado más sensibles a la problemática.

En las vicisitudes del movimiento de mujeres no han faltado las críticas provenientes del exterior que pretenden devolver al mundo de lo no civil la acción colectiva de las mujeres. Esto ha ocurrido curiosamente a partir de la misma base de sus demandas que parecieran tener toda legitimidad. Estos actores han tratando de minimizar las implicaciones de sus exigencias, y el carácter del movimiento. Al respecto menciona una activista:

una vez esta periodista, Lolita de la Vega, qué por qué tanto reclamo si el Estado de México era más severo el feminicidio, pues es por eso, por la valentía de la gente de aquí, por la fuerza, la gente que tiene el empeño ya perdió el miedo por eso la gente nos tiene miedo, porque nosotros no lo tenemos (risas). Lo hacemos que parezca invisible.

La narrativa permite observar que el reclamo que hacen las mujeres en la frontera norte puede ser visto como un atributo negativo al movimiento social. Desde los contracódigos la protesta, no es atributo de las mujeres, ya en otros estudios sobre el movimiento de mujeres en Chihuahua se ha apuntado que en el discurso de los sectores opositores la presencia de las mujeres no corresponde a la escena pública, sino a la privada. Por ello protestar, reclamar, quejarse visto desde una esfera intrusiva como lo es lo íntimo y lo privado, no cabe como un atributo de las mujeres ${ }^{11}$. Es nuevamente la referencia reduccionista y estigmatizadora referente a que una mujer en la escena pública: haciendo visible, protestando, tiene el carácter de mujer pública en su más degradante expresión. Ser mujer pública se equipará en Ciudad Juárez a ser prostituta a alguien que ofrece y vende su cuerpo, una persona que no merece ser considerada en la esfera civil (Schmidt, 2007).

Como un código relativo a lo considerado civil desde el movimiento de mujeres se plantea, como puede verse en la cita textual anterior, la valentía, perder el miedo, la fuerza pero también el trabajo como factores que refiere a la participación y al movimiento de las mujeres. La fuerza 
a lo largo de las entrevistas se utilizó en varias ocasiones como sinónimo de la capacidad que dan las redes para el logro de objetivos; además del mismo movimiento abrevan la valentía y la pérdida del miedo; por otro lado, la acción colectiva, las acciones de protesta, las movilizaciones, las demandas ante el gobierno han sido catalogadas como trabajo por parte de las entrevistadas. Esta es una forma de utilizar los códigos que remiten a la inclusión de la esfera civil. Es decir, asumir categorías puras o previamente sacralizadas para patentar y legitimar su lucha, así como debilitar y desmembrar el contra-código de la mujer que pertenece a la esfera íntima y no es meritoria de derechos.

Desde el gobierno en donde se toman las decisiones de políticas públicas relativas a los problemas que enfrentan las mujeres de Chihuahua, es importante ver como la esfera del poder interfiere en el mundo de lo civil. De acuerdo con nuestras informantes esto sucede a partir de minimizar los problemas, hacerlos invisibles, ya sea como un acto volitivo de los políticos en turno o no, o simplemente reproduciendo los contra-códigos que impiden la inclusión, lo que no los exime de sus responsabilidades. Al respecto una entrevistada apunta,

Cuando iba a llegar este gobierno (estatal en 2012) batallamos mucho para la reunión con el gobernador, había habido reunión con otros candidatos pero con este ha sido difícil, incluso pues la percepción que teníamos de pronto es que él no sabía que era el movimiento de mujeres en el estado de Chihuahua.

$\mathrm{Al}$ respecto la omisión del gobernador para reunirse con las asociaciones del movimiento refiere a la intensión de minimizar las demandas, de hacer creer a la ciudadanía que este problema, es un problema menor, que se atenderá pero no tiene prioridad. A pesar de la gran promoción a nivel nacional e internacional en el que las asociaciones de mujeres han sido exitosas, a pesar de la sentencia de una instancia internacional como lo es la Corte Interamericana de los Derechos Humanos ${ }^{12}$. De hecho el activismo de las mujeres en Chihuahua les ha permitido en los diferentes ámbitos de gobierno ser interlocutoras legítimas desde hace ya algunos años, como bien lo apuntaba una académica e investigadora:

En Chihuahua los políticos ya no pueden no darte la cara, desde hace algunos años los candidatos deben tener un desayuno con las organizaciones de la sociedad civil. Tienen que formar comités con las organizaciones de la sociedad civil [Como funcionario] ya no puedes hacer lo que se te pegue la gana porque el costo político puede ser muy alto [] Trabajamos juntos [con el gobierno] porque para ti [funcionario público] mi recurso es políticamente correcto, porque te puede entrar mucho dolor de cabeza, y porque en el mejor de los casos podemos trabajar juntos a favor la sociedad ${ }^{13}$.

Este conjunto de cosas, como es el intentar desestimar el papel de las asociaciones, cruza con que la justicia tiene efectos diferenciadores para 
las mujeres en el mundo de lo civil. Menciona una de las entrevistadas que en la reunión que se concretó al iniciar la gestión del actual gobernador de la entidad, una de las madres de las mujeres asesinadas lo increpó de la siguiente manera:

haber señor gobernador díganos cuánto valía la vida de su sobrino, y le dice: no pues cuánto pidió por la vida de su sobrino [] "pues la cadena perpetua”. Y pues cuánto cree que valía la vida de mi niña de 14 años, le preguntaban y decía: “pues igual”. Pues le dieron once años al hombre, y en menos de cinco va a salir, eso cree qué valía la vida de mi niña.

En el problema del feminicidio, el tema de la justicia esta irresuelto, el hartazgo se muestra en las madres y familiares que no han recibido justicia por parte de las instancias de gobierno, y estas a pesar de la intervención de las agencias de justicia internacionales no ha dado respuesta efectiva a este problema de amplio calado para la sociedad chihuahuense y la mexicana en su conjunto.

Por otro lado, en la gestión con las instancias gubernamentales para la generación de políticas públicas, con amplios esfuerzos las asociaciones y el movimiento después de veinte años han concretado recientemente la creación del Instituto Chihuahuense de la Mujer (2005), los Centros de Justicia para las Mujeres (2012), la inserción en el Plan de Desarrollo y en el Presupuesto con perspectiva de género. Estas instancias gubernamentales sin embargo, han tenido tras de sí una característica permanente: la falta de continuidad, la ineficacia, y predominio político sobre el profesionalismo.

A estos avances de manera frecuente las entrevistadas señalaron que sus logros solo se encontraban en el papel como elemento que es favorable pero que no alcanza a convertirse en un código que impacte en la sociedad civil, estar en el papel implica su falta de aplicación, el poder ser borrado o quitado del mismo en cualquier momento. Por otro lado, a pesar de la gran movilización y presencia de las mujeres desde el movimiento en la escena pública, los gobiernos tratan de limitar su parcela de influencia, lo que genera una constante pugna, para evitar la exclusión de la toma de decisiones que les atañe.

Las narrativas que ofrecen las mujeres que forman parte de las asociaciones civiles y del movimiento social en Ciudad Juárez permiten observar que sus acciones no se enfocan exclusivamente en las agencias gubernamentales, su lucha se ha ido enfocando por la transformación de los códigos en las audiencias que representan los otros ciudadanos, para así sostener una legitimidad moral que de pauta a las transformaciones en la esfera civil basada en la solidaridad. Esto ha sido, paradójicamente, acompañado no sólo por montar el escenario en el Estado-nación, sino ir más allá a los referentes supranacionales. La lucha del grupo minoritario de mujeres en Juárez no está ganada, sin embargo, como mencionaba una entrevistada la política ahí va funcionando lentamente. 


\section{Comentarios finales}

En frontera norte de México asistimos en los últimos años a un incremento de la violencia hacia las mujeres -al menos debido a su parcial visibilización, se considera que este fenómeno es reciente-, nos encontramos con el reconocimiento de la existencia de un entorno violento que minimiza la condición de ser mujer en la esfera pública, que desconoce sus derechos a la seguridad, la justicia, el acceso a bienes y servicios, la representación política y en el peor de los casos a un derecho fundamental como es la vida. Estos hechos refieren al desconocimiento velado del carácter de ser ciudadanas, situándolas en la sociedad civil en una condición de inequidad y exclusión.

Un sector de mujeres ha logrado identificarse y configurarse como un grupo minoritario al que se le han vedado sus derechos en el marco de la ciudadanía y la sociedad civil existente. Su involucramiento en la protesta sostenida desde los principios morales que se encumbran en una sociedad civil incipiente en el nivel internacional (Soysal, 1994) principalmente, implica una reversión de los discursos que se encuentran en la esfera civil local. Al menos desde la construcción discursiva de las mujeres entrevistadas que pertenecen a las asociaciones y al movimiento de mujeres en Ciudad Juárez podemos identificar como estas reconstruyen sus narrativas que no queda en el nivel local o nacional, sino en uno ulterior, instalándose en el nivel del sistema de derechos en una esfera civil internacional que proclaman la defensa de las mujeres ante la violencia y la exclusión, con referentes en el movimiento feminista internacional. La lógica del discurso de las activistas permite observar la confrontación que realizan al gobierno, los objetivos que se plantean como movimiento, así como los elementos que esgrimen la identidad de las mujeres, y sus intereses que van más allá de sus propias asociaciones. Las lógicas discursivas que tratan permiten observar las formas en las que se comparten ciertos códigos y las narrativas que permiten dilucidar la exclusión de las mujeres. De este modo se plantea como se establecen los entendimientos y comprensiones acerca de los motivos de las mujeres para ser incorporadas en la sociedad civil con un sentido moral y solidario, lo mismo ocurre en el ámbito de las relaciones que se establecen en el nivel de la esfera pública y se intenta reconfigurar, así mismo las instituciones que se instalan en el sistema de valores y acciones de las organizaciones públicas.

Las narrativas que sostienen sus actos performativos tienen la intención de hacer patente su inclusión, que es al final y al cabo es la inclusión de las otras féminas, a través de un llamado a la solidaridad de la esfera civil. Paradójicamente, y a menara de comentario al calce, esto ha funcionado en el nivel internacional que en términos simbólicos puede ser importante, pero que al no encontrar referentes vinculantes se ve limitado en su avance; por otro lado, la guerra contra el narcotráfico política impulsada por el gobierno del presidente Calderón dio la espalda a la lógica de reducción de la violencia en la localidad, lo que impacto en términos de inclusión de las mujeres a la esfera civil, y de hecho coartó los derechos a otros 
grupos marginados como los jóvenes, migrantes, adictos, y sectores empobrecidos. A pesar de esta contingencia, en el incremento de la violencia, el grupo que ha generado identidad y acciones concretas continua su marcha hacia implantar referentes en diferentes espacios que lleven a la institucionalización de una sociedad civil que incluya a las mujeres y las involucre en el escenario de los derechos y civilidad. 


\section{Notas}

${ }^{1}$ Ponencia presentada en la Novena Conferencia de la ISTR Regional, Santiago de Chile, agosto 2013.

${ }^{2}$ Esto es retomar los derechos que se configuran en una ciudadanía posnacional, más allá de las fronteras de los derechos nacionales que trascienden a una sociedad civil de carácter global (Soysal, 1994).

${ }^{3}$ La propuesta de Alexander, a diferencia de otros autores de la sociedad civil, no se reconoce en su principio utilitarista, en su apartado pluralista, o en su énfasis comunicativo. Cohen y Arato dos de los autores más influyentes en las discusiones sobre la sociedad civil desde la teoría política en los últimos años, han sido criticados -tal vez injustificadamente y de forma escasamente argumentada (Arato, 1999)- por considerar a la sociedad civil como una arena donde sus participantes tienen una autonomía prácticamente asegurada, y dados sus tintes de carácter normativo al poner énfasis en un principio teleológico democratizador (p.e. Cansino, 1997). Al respecto considero que estas valoraciones no son fructíferas para los fines de este documento, además de que lo rebasan pueden restringirlo, por ello, y dada una versión alternativa basada en la solidaridad, considero poner atención a la propuesta de esfera civil de Jeffrey Alexander.

${ }^{4}$ El universalismo tiene diferentes fuentes de constitución desde el pacto civil originario que le dio vida, los fundadores, y a partir de la reelaboración del mismo mediante la injerencia de los particularismos y la contaminación de las otras esferas no civiles.

${ }^{5}$ Aunque diferentes cuerpos ya habían sido encontrados en diferentes partes y alrededores de Ciudad Juárez, los ocho cuerpos descubiertos en el Campo Algodonero en 2001 fue el detonante para conformar un movimiento importante y construir alianzas y redes. Al respecto una activista menciona: aun cuando ya habíamos hecho acciones de denuncia, de exigencia de justicia desde diferentes frentes, pues eso logró conjuntar algo que se llamó la Red Ciudadana de la No Violencia, a partir de ese hecho y que nos integramos diferentes organizaciones, desde lo individual, desde profesionistas, desde universitarias, maestras de la universidad confluíamos en ese espacio.

${ }^{6}$ En agosto de 2012 se entrevistaron a cinco mujeres activistas de tres asociaciones pertenecientes al movimiento que pugna contra el feminicidio: Mujeres por México, Casa Amiga Centro de Crisis, Red Mesa de Mujeres de Ciudad Juárez.

${ }^{7}$ De aquí en adelante los entrecomillados referirán a las citas textuales de las informantes.

${ }^{8}$ A partir de aquí los códigos obtenidos de las entrevistas se colocan en negritas.

${ }^{9}$ En Chihuahua se reconoce que existe una importante participación de mujeres en las asociaciones de carácter asistencialista (véase Martínez, 2011).

${ }^{10}$ Entre estos destacan las diferentes fiscalías de atención a los crímenes contra las mujeres, el Instituto Chihuahuense de la Mujer, el Centro de Justicia para las Mujeres, la Ley Estatal del Derecho de las Mujeres a una Vida Libre de Violencia, entre otras instancias con funcionamiento regular y todavía marginal a las demandas, pero que representan importantes avances. 
${ }^{11}$ En este mismo tenor existen otras categorías que algunos investigadores han tratado como la del lucro y la responsabilidad por desincentivar la inversión. La primera como una estrategia del gobierno para generar división entre los familiares de las víctimas y las asociaciones al considerar que estas últimas obtenían recursos de agencias internacionales a partir del dolor de las personas (véase Wright, 2007). Así mismo los empresarios culparon al movimiento por promover la imagen de una ciudad violenta y ser un lastre al crecimiento económico de la localidad (véase Monárrez, 2007).

${ }^{12}$ El caso del Campo algodonero vs México fue promovido en la CIDH en 2003 por asociaciones de derechos humanos mexicanos, después de haber sido encontrados ocho cuerpos de mujeres asesinadas en los campos en donde se solía cosechar algodón en Ciudad Juárez.

${ }^{13}$ Entrevista con Ana María De la Rosa, activista social y académica, 3 de septiembre de 2010. 


\section{Bibliografía}

Alexander, J.C. (1997), “The Paradoxes of Civil Society”. International Sociology 12, 115133.

Íbidem (2000), “Ciudadano y enemigo como clasificación simbólica: sobre el discurso polarizador de la sociedad civil”, en Sociología Cultural. Formas de clasificación en las sociedades complejas. Anthropos, Barcelona.

Íbidem (2006), The civil sphere, Oxford University Press, New York.

Arato, Andrew y Jean Cohen (1999), "Esfera pública y sociedad civil”, Metapolítica, vol. 3, núm. 9, pp. 37-55.

Bobes, Velia (2002), “Movimientos sociales y sociedad civil: una mirada desde América Latina”, Estudios Sociológicos, vol. XX, núm. 59, pp. 371386.

Íbidem (1995), "La utilidad de la virtud: un estudio de la ciudadanía en Cuba: 1898-1994”, Perfiles latinoamericanos, núm. 7, pp. 199-224.

Cansino, César y Sergio Ortiz (1997), "Nuevos enfoque sobre la sociedad civil”, Revista Latinoamericana de Estudios Avanzados, núm. 3, eneroabril, pp. 1-15.

Geertz, C. (1989), La interpretación de las culturas, Gedisa, Barcelona.

Janoski, Thomas (1998), Citizenship and Civil Society. A Framework of Rights \& Obligations in Liberal, Traditional, and Social Democratic Regimes, Cambridge University Press.

Marshall, T.H. (1965), Class, citizenship and social development, Anchos Books, Dobleday, Nueva York.

Martínez Carmona, Carlos A. (2011), Entendiendo el entorno favorable para las asociaciones. El caso de la ciudad de Chihuahua, Editorial Académica Española, Madrid.

Massal, Julie (2007), “Sociedad civil internacional: ¿un poder global?”, Análisis político, núm. 61, pp. 54-72.

Monárrez Fragoso, Julia Estela y María Socorro Tabuenca [coordinadoras] (2007), Bordeando la violencia contra las mujeres en la frontera norte de México, Porrúa/Colegio de la Frontera Norte, México.

Okin, Moller S. (1996), “Liberalismo político, justicia y género”, en C.Castells (comp.), Perspectivas feministas en teoría política, Paidós, Barcelona. 
Pérez García, Martha (2011), Luchas de arena: las mujeres en Ciudad Juárez, Universidad Autónoma de Ciudad Juárez, Chihuahua.

Portillo, Lourdes [directora] (2001), Documental: Señorita extraviada.

Schmidt Camacho, Alicia (2007), "La ciudadana X. Reglamentando los derechos de las mujeres en la frontera México-Estados Unidos”, en Monárrez Fragoso, Julia Estela y María Socorro Tabuenca [coordinadoras], Bordeando la violencia contra las mujeres en la frontera norte de México, Porrúa/Colegio de la Frontera Norte, México.

Soysal, Y. N (1994), Limits of Citizenship: Migrants and Postnational Membership in Europe, University of Chicago Press, Chicago.

Tarrés, M.L (Coord.) 1999, Género y cultura en América Latina, El Colegio de México, México.

Terrén, Eduardo (2003), “La ironía de la solidaridad: cultura, sociedad civil y discursos sobre el conflicto racial de El Ejido”, Revista Española de Investigaciones Sociológicas, núm. 102, pp. 125-146.

Young, I.M. (1996), "Vida política y diferencia de grupo: una crítica del ideal de ciudadanía universal”, en C. Castells (comp.), Perspectivas feministas en teoría política, Paidós, Barcelona.

Wright, Melissa (2007), “El lucro, la democracia y la mujer pública: estableciendo las conexiones”, en Monárrez Fragoso, Julia Estela y María Socorro Tabuenca [coordinadoras], Bordeando la violencia contra las mujeres en la frontera norte de México, Porrúa/Colegio de la Frontera Norte, México.

Recibido: 15.10 .2013

Aceptado: 13.12.2013 